\title{
O CONCEITO DE ESTADO EM MAX WEBER
}

Alvaro Bianchi

O objetivo deste ensaio é apresentar o conceito weberiano de Estado. O tema não é novo e muito já foi dito e escrito a respeito. A sociologia da dominação weberiana, da qual o conceito de Estado é um capítulo, tem sido um dos aspectos mais analisados e discutidos de sua obra. Mas o desenvolvimento dos estudos weberianos nas últimas décadas tem lançado uma nova luz sobre a obra desse autor. Aspectos biográficos que eram dados como indiscutíveis desde a biografia de Marianne Weber (2003) têm sido questionados por novas abordagens, questões metodológicas consideradas resolvidas foram inovadoramente retomadas, conceitos analisados à exaustão têm sido novamente colocados em discussão (Swedberg, 2003).

Importante para os propósitos deste ensaio é um conhecimento mais apurado a respeito da composição de sua principal obra: Wirtschaft und Gesellschaft (Economia e sociedade $)^{1}$. Weber começou a trabalhar nessa obra em 1909

\footnotetext{
${ }^{1}$ Sobre a composição de Wirtschaft und Gesellschaft, ver os importantes artigos de Mommsen (2000) e Pierucci (2008).
} 
e, inicialmente, ela deveria compor apenas uma parte de um novo manual de economia política dedicado àquilo que se poderia chamar de aspectos sociais da economia. Em seu longo processo de maturação, o plano das matérias que deveriam constituir essa parte foi sucessivamente modificado e o trabalho nela sofreu uma longa interrupção durante a Primeira Guerra Mundial. Quando Weber decidiu retomar o projeto, em 1918, já o via com outros olhos e decidiu concentrar-se, primeiramente, em uma apresentação formal das categorias sociológicas nas quais havia trabalhado. Trabalhou para tal a partir do ensaio Über einige Kategorien der verstehenden Soziologie ("Sobre algumas categorias da sociologia compreensiva”), que havia escrito entre o final de 1912 e o início de 1913 e publicado neste ano na revista Logos. Segundo narrou sua esposa, em 1918 e 1919 Weber ministrou cursos em Viena e Munique a respeito dessas categorias, ocasiões que lhe permitiram retomar suas anotações e 80 submetê-las a profunda reelaboração (Weber [Marianne], 2003, p. 792). A versão final de apresentação das soziologische Kategorienlehre ultrapassou em muito as escassas páginas do ensaio inicial, uma vez que reformulou radicalmente muitos conceitos e ampliou enormemente o escopo.

Depois de mais de dez anos de trabalho, de várias reformulações do projeto e de muita insistência por parte de seu editor, o sociólogo alemão encaminhou para publicação um conjunto de quatro capítulos recém-finalizados, que deveriam compor sua obra. Esses capítulos receberam os títulos de Soziologische Grundbegriffe ("Conceitos sociológicos fundamentais"), Soziologische Grundkategorien des Wirtschaftens ("Categorias sociológicas fundamentais da gestão econômica"), Die Typen der Herrschaft ("Os tipos de dominação"), Stände und Klassen ("Estamentos e classes") e compuseram as soziologische Kategorienlehre apresentadas como primeira parte da magnum opus de Weber pelas sucessivas edições. Mas a morte o surpreendeu quando a edição 
do livro estava em suas fases iniciais. Trabalhando com os materiais deixados por Weber em seu escritório, sua esposa reuniu textos escritos entre 1909 e 1914, supostamente para o projeto original de Wirtschaft und Gesellschaft, e os publicou como uma segunda parte dessa obra, logo após as soziologische Kategorienlehre apresentadas como primeira parte. Segundo afirmou Frau Weber no prefácio à primeira edição de Wirtschaft und Gesellschaft, essa segunda parte poderia ser designada "como Sociologia 'concreta' em contraposição à 'abstrata' da primeira parte” (Weber, 1999, v. 1, p. XIL).

O objetivo da esposa de Weber era apresentar essa obra como uma construção acabada e unitária e, ao mesmo tempo, acessível ao público ${ }^{2}$. Wirtschaft und Gesellschaft ganhou ares de sistema completo, com a intervenção de Johannes Winckelmann, curador da quarta e quinta edições. Winckelmann procurou dar mais coerência ao texto e, para isso, "não hesitou em cobrir lacunas com textos que ele mesmo compôs, recortando e colando trechos de outras obras de Weber, escritas com outros objetivos e outros dispositivos conceituais" (Pierucci, 2008, p. 45). Na seção dedicada ao Estado (Seção 8 do capítulo IX), a que mais sofreu com esse procedimento, foram inseridos trechos que originalmente compunham escritos políticos de Weber nem sempre coerentes com as definições categoriais desenvolvidas posteriormente.

Uma apresentação do conceito weberiano de Estado não pode deixar de seguir os passos de Weber e reconstruir atentamente a intrincada rede conceitual, por meio da qual pretendia assentar sua sociologia da dominação. A reconstrução do método de exposição não diz tudo, entretanto, a respeito desse conceito que se pretende aqui expor. Dois são os problemas de uma reconstrução estreita: primeiro assume

\footnotetext{
${ }^{2}$ Não era fácil assimilar as soziologische Kategorienlehre, como ainda não o é. Ministrando um curso sobre elas, Weber recebeu pedido dos alunos para que suspendesse as lições destas e ministrasse aulas sobre temas históricos mais concretos (cf. Weber, [Marianne] 2003).
} 
como pressuposto que a obra de Weber encontrava-se acabada ou de que qualquer uma das edições de Wirtschaft und Gesellschaft acertou ao reproduzir a intenção do autor e, depois, restringe o âmbito da produção teórica a seu resultado publicado, obnubilando as determinações desse processo de produção.

A apaixonada defesa que Weber fez de uma ciência livre de pressupostos confundiu muitos comentadores. Ciência e política não são, para Weber, duas esferas antagônicas da atividade humana, nem estão estritamente separadas. Pelo contrário, advogou sempre em defesa da transparência das relações entre ciência e política, como uma maneira de evitar a demagogia (cf. Mommsen, 1992, p. 10). Mas sua atividade política era intensa como demonstraram a biografia que sua mulher Marianne Weber (2003) escreveu e a alentada pesquisa de Mommsen (1990).

Max Weber nem sempre quis separar de modo tão níti82 do sua posição de professor de suas idéias políticas, como pretenderam seus interpretes. Em sua aula do dia 19 de janeiro de 1920, por exemplo, elevou a voz contra os nacionalistas que se recusavam a retirar as injúrias que haviam lançado contra social-democratas na véspera: "Todo aquele que não o fizer será Hundsfott [filho de uma cadela]!" (Weber, [Marianne] 2003, p. 788). Chamar um aluno de Hundsfott não é impor "suas opiniões políticas pessoais" $\mathrm{e}$ fazer o contrário do que recomendava em seu conhecido ensaio Wissenschaft als Beruf ("Ciência como vocação")?

Mas aqui não importa considerar as dificuldades para adequar uma prática intelectual a um postulado que exigia total desprendimento das ideias políticas. O que importa é registrar que uma separação ingênua entre ciência e política poderia ter como consequência uma valorização unilateral

\footnotetext{
${ }^{3}$ Weber (1982, p. 173) afirmava que um professor deveria abster-se de expor em aula "suas opiniões políticas pessoais".
} 
da atividade científica do sociólogo alemão e uma subvalorização de sua atividade política. Tal separação acarretaria uma desvalorização do impacto dessa atividade sobre sua pesquisa científica e um conhecimento superficial de suas motivações.

\section{Estado como associação política (politischer Verband)}

O modo como o conceito weberiano de Estado foi interpretado esteve fortemente marcado por dois acontecimentos editoriais. Já foi feita referência a um deles: a publicação, de Wirtschaft und Gesellschaft como uma obra unitária e acabada, primeiro por Marianne Weber e depois por Johannes Winckelmann. O segundo acontecimento tem lugar fora da Alemanha e foi mais importante para a recepção que Weber teve nos Estados Unidos e mesmo no Brasil: a publicação de From Max Weber: Essays in Sociology por C. Wright Mills e H. H. Gerth em $1947^{4}$. Essa notável coletânea tinha o mérito de arranjar tematicamente passagens da difícil Wirtschaft und Gesellschaft, além de publicar ensaios e conferências de Weber, de leitura sem dúvida mais acessível do que essa obra. Dentre esses textos, destaca-se a conferência Politik als Beruf ("A política como vocação”), pronunciada em 1918 na Universidade de Munique.

Segundo Marianne Weber, o pano de fundo dessa conferência era "o colapso da Alemanha, o bolchevismo e a inquietude milenarista dos jovens" (Weber, [Marianne] 2003, p. 799). Sem se restringir, entretanto, à análise da conjuntura política da Alemanha e da Europa da época, Max Weber procurou nela, tomando uma perspectiva universalizante, demonstrar que "o recurso específico, embora não o único do Estado foi, em todos os tempos, a dominação baseada na violência física legítima, e que a política sempre

\footnotetext{
${ }^{4}$ Sobre a divulgação das ideias de Weber nos Estados Unidos, deve-se destacar, também, o empenho de Talcott Parsons, que traduziu para o inglês e publicou, em 1930, The protestant ethic and the spirit of capitalism e, em 1947, o volume 1 de Wirtschaft und Gesellschaft, com o título The theory of social and economic organization.
} 
significa a luta por uma parte do poder político" (Weber, [Marianne] 2003, p. 799). A exposição de Max Weber parece estar dirigida não apenas contra movimentos políticos que tinham lugar à época, como também contra a metafísica do Estado corrente na Staatslehre (teoria do Estado) alemã, e principalmente entre os discípulos de Von Gierke, que destacavam Das deutsche Genossenschaftsrecht (o direito alemão da cooperação) como o fundamento do Estado (cf. Lassman, 2000, p. 87).

Em sua conferência, Weber interrogou-se a respeito do significado de uma "associação" política (ein politischer Verband) e do próprio Estado (Staat). Uma definição não idealizada dessas realidades sociais implicava, para o sociólogo alemão, a recusa de conceitos propriamente normativos. Descartando assim toda definição que remetesse aos fins do Estado, procurou uma definição sociológica nos meios que seriam próprios a este: "Em última análise só podemos 84 definir o Estado moderno sociologicamente em termos dos meios específicos peculiares a ele, como peculiares a toda associação política (politischen Verband), ou seja, o uso da força física" (Weber, 1982, p. 98; 1988, p. 506).

E, a seguir, apresentou seu conhecido conceito: "O Estado é aquela comunidade humana que, dentro de determinado território - este, o 'território', faz parte de suas características - reclama para si (com êxito) o monopólio da coação física legítima"5 (Weber, 1982, p. 98). A definição é, palavra por palavra, idêntica àquela apresentada no capítulo IX de Wirtschaft und Gesellschaft (Weber, 1980, p. 822), revelando o uso, por parte do editor Johannes Winckelmann, dos escritos políticos de Weber para a composição desse capítulo.

\footnotetext{
${ }^{5}$ No original: "Staat ist diejenige menschliche Gemeinschaft, welche innerhalb eines bestimmten Gebietes - dies: das 'Gebiet' gehört zum Merkmal - das Monopol legitimer physischer Gewaltsamkeit für sich (mit Erfolg) beansprucht” (Weber, 1988, p. 506).
} 
A forjada coincidência editorial entre o texto da conferência de 1918, difundido por Mills e Gerth, e partes do capítulo IX da quinta edição de Wirtschaft... teve como consequência uma apropriação mutilada do conceito weberiano de Estado, que tendeu a reduzi-lo à mera sede da violência legítima. A definição presente em Politk als Beruf não representa, entretanto, o ponto final da elaboração weberiana do conceito de Estado. A sociologia política weberiana é uma sociologia da dominação, que considera a força e a violência como momentos essenciais do processo político e da própria existência e funcionamento das instituições políticas (cf. Vincent, 1998, p. 71). Esses momentos essenciais, que já haviam sido fortemente enunciados na conferência de 1918, não esgotavam, entretanto, toda a sociologia da dominação e nem mesmo o conceito de Estado.

Nas soziologische Kategorienlehre, o sociólogo alemão julgou necessário retomar esse conceito, submetendo-o a uma profunda reelaboração. Segundo sua esposa, ele teria tomado notas a respeito de sua teoria das categorias sociológicas para as aulas que deu em Viena em 1918 e em Munique em 1919. Ainda no começo de 1920, Weber estava "retocando os difíceis conceitos e fez muitas mudanças nas folhas de prova" (Weber, [Marianne] 2003, p. 792). Esse texto tardio começava com uma importante exposição metodológica. E era nesse contexto primeiramente metodológico que Weber fez sua primeira menção ao conceito de Estado:

Para outros fins e conhecimento (por exemplo jurídicos) ou de finalidade práticas, por outro lado, pode ser conveniente e mesmo inevitável tratar de determinadas formações sociais ("Estado", "cooperativa", "sociedade por ações", "fundação") como se fossem indivíduos (por exemplo como detentores de direitos e deveres ou como agentes em ações juridicamente relevantes). Para a interpretação compreensível das ações pela Sociologia, ao contrário, essas formações 
nada mais são do que desenvolvimentos e concatenações e ações específicas de pessoas individuais, pois só estas são portadoras compreensíveis para nós de ações orientadas por um sentido (Weber, 1999, v. 1, p. 9).

Nesse contexto, o Estado era apresentado como uma forma social não individualizável, ou seja, não como um ente e sim como um feixe de ações protagonizadas por indivíduos. Alguns comentadores (ver, p. ex., Andreski, 1964) apontaram que o individualismo metodológico weberiano presente nessa seção das soziologische Kategorienlehre estaria em contraste com a análise estrutural-formal que teria lugar em outros momentos da mesma obra. Os diferentes níveis de abstração da exposição são evidentes, conforme destacado por Marianne Weber, e, nos momentos mais concretos desta, Weber tende a considerar essas "formações sociais", dentre as quais o Estado, como instituições que não são redutíveis à simples soma de ações individuais.

Embora estivesse fortemente influenciado pela economia neoclássica, em particular pela Escola Austríaca (cf. Clarke, 1991, pp. 261-65), Weber não estava disposto a reduzir as formações sociais a agregados mecânicos das ações de uma multiplicidade de indivíduos. A constelação das ações individuais daria origem, para ele a formações sociais mais ou menos estáveis, que não poderiam ser reconduzidas novamente às ações originais ${ }^{6}$. Mas a congruência entre a exposição analítico-categorial da primeira parte de Wirtschaft und Gesellschaft, particularmente do conceito de Estado, e a análise estrutural-formal da segunda parte pode ser menor do que a apontada por Dusza, uma vez que, como visto, essa obra é muito menos orgânica e unitária do que se pensava há algumas décadas.

${ }^{6}$ Ver, a respeito, o argumento de Dusza (1989, p. 73). 
O individualismo metodológico assumido por Weber é crucial, todavia, para compreender seu conceito de Estado como uma "relação de dominação de homens sobre homens", na qual os dominados submetem-se à autoridade invocada pelos dominantes (Weber, 1999, v. 2, p. 526). Na medida em que "as 'relações' existem apenas como ações humanas de determinado sentido" (Weber, 1999, v. 1, p. 24), fica claro que o Estado não pode ter uma existência separada dos indivíduos. A concepção weberiana do Estado é, assim, uma concepção subjetiva, de acordo com a tipologia estabelecida por Georg Jellinek, uma vez que o Estado, em vez de ser um ente objetivo completamente separado da vida, "consiste em relações de vontade de uma variedade de homens. Formam o substrato desse Estado homens que mandam e homens que obedecem"7 (Jellinek, 2000, p. 190). Esclarecido esse aspecto metodológico do conceito de Estado, é possível passar a uma análise mais substantiva.

Poder e dominação são os conceitos primeiros dessa sociologia da dominação e aqueles a partir dos quais se tornava possível a reconstrução do conceito de Estado. Para Weber (1999, v. 1, p. 33), o poder (Macht) "significa toda probabilidade de impor a própria vontade numa relação social, mesmo contra resistências". Tal conceito seria, entretanto, pouco útil para a análise das relações sociais, uma vez que todo indivíduo poderia pôr outro em uma situação na qual este último seria obrigado a aceitar sua vontade. Em uma relação entre empregado e empregador, ambos teriam, por exemplo, em situações diversas, poder para fazerem valer suas vontades no mercado de força de trabalho sem que fosse possível determinar de antemão qual das partes prevaleceria.

É devido a esse caráter sociologicamente amorfo do conceito de poder que Weber prefere usar o conceito de

${ }^{7}$ Todas as traduções de trechos incluídos neste artigo foram feitas por este autor. 
dominação (Herrschaft), que não seria senão um caso especial do poder (Weber, 1999, v. 2, p. 187): dominação significa "a probabilidade de encontrar obediência a uma ordem de determinado conteúdo, entre determinadas pessoas indicáveis" (Weber, 1999, v. 1, p. 33) ${ }^{8}$. A situação de dominação seria, então, aquela na qual uma ou várias pessoas encontram-se em condições de mandar eficazmente em outras. $\mathrm{O}$ conceito de dominação seria, assim, idêntico ao conceito de "poder de mando autoritário" (Weber, 1999, v. 2, p. 191). O caráter equívoco do conceito de poder é suprimido pelo conceito de dominação, uma vez que este implicaria uma probabilidade e, portanto, permitiria prever em dada relação qual das partes conseguirá impor sua vontade.

Ter-se-ia uma associação de dominação quando os membros dessa associação estivessem submetidos a situações de dominação em virtude de uma ordem que regula as relações entre seus membros. O conceito de associação 88 (Verband) ocupa uma posição central na reelaboração weberiana do conceito de Estado. Por associação, Weber (1999, v. 1, p. 30 ) entende

[...] uma relação social fechada para fora ou cujo regulamento limita a participação quando a observação de sua ordem está garantida pelo comportamento de determinadas pessoas, destinado particularmente a esse propósito: de um dirigente e, eventualmente, um quadro administrativo que, dado o caso, têm também, em condições normais, o poder de representação ${ }^{9}$.

\footnotetext{
8 “Por 'dominação' compreenderemos, então, aqui, uma situação de fato em que uma vontade manifesta ('mandado') do 'dominador' ou dos 'dominadores' quer influenciar as ações de outras pessoas (do 'dominado' ou dos 'dominados'), e de fato as influencia de tal modo que estas ações, num grau socialmente relevante, se realizam como se os dominados tivessem feito do próprio conteúdo do mandado a máxima de suas deliberações ('obediência')" (Weber, 1999, v. 2, p. 191).

${ }^{9}$ Não é simples traduzir Verband, como se pode ver na discussão levantada por Talcott Parsons na década de 1940. Segundo registrou o sociólogo estadunidense
} 
A terminologia ecoava a distinção de Ferdinand Tönnies entre a Comunidade (Gemeinschaft) constituída por laços emocionais de natureza pessoal e a Sociedade (Gesellschaft) determinada por relações racionais entre seus membros. Weber considerava, entretanto, o conceito de comunidade de modo mais abrangente, abarcando todos os tipos de relações sociais (cf. Mommsen, 2000, p. 375). Do mesmo modo, para a associação, seria indiferente se a relação que nela tem lugar é de tipo comunitário ou associativo. $\mathrm{O}$ traço distintivo da associação de outras formas de relação é que nesta estaria presente, e seria facilmente identificável, um dirigente ou um quadro administrativo em condições de "pôr em prática a ordem da associação" (cf. Mommsen, 2000, p. 375). A distinção e especialização de funções administrativas responsável pela preservação de uma determinada ordem articula-se, desse modo, a uma hierarquia dos indivíduos no interior de uma relação social.

Uma associação de dominação era denominada por Weber associação política (politischer Verband) "quando e na medida em que sua subsistência e a vigência de suas ordens, dentro de determinado território geográfico, estejam garantidas de modo contínuo mediante a ameaça e a aplicação de coação física por parte do quadro administrativo" (Weber, 1999, v. 1, p. 34.). Os elementos básicos que podem ser extraídos dessa definição são, assim, um território

em uma nota de rodapé ao texto de Weber, o "termo Verband, o qual é um dos mais importantes no esquema weberiano foi no sentido técnico definido neste parágrafo traduzido como 'corporate group'. A palavra 'Association' não foi usada porque ela não implica a diferenciação formal entre a cúpula ou o chefe e os membros ordinários. Uma 'corporação' é, deste ponto de vista, uma forma específica de corporate group" (Weber, 1964, p. 145, nota). Entretanto, a escolha terminológica de Parsons restringiu enormemente o alcance do conceito pretendido por Weber, além de criar confusão com o conceito de corporação. Está, portanto, certo Dahrendorf (1959, p. 167) ao insistir na inadequação do conceito de "grupo" e ao propor traduzir Verband por "association". Sobre os problemas próprios da interpretação parsoniana da obra de Weber e, particularmente, de sua sociologia da dominação, ver Cohen, Hazelrigg e Pope (1975). 
ordenadamente dominado; a capacidade e a disposição para o uso da força sempre que for necessário; uma ação social não exclusivamente econômica; e um quadro administrativo. Em outras palavras:

(a) uma associação política é espacialmente definida e delimitada. A relação de dominação que ela encerra tem um lugar em um território definido em certo momento. Desse modo, todos os que se encontram dentro desse território estão submetidos à ordem que é própria dessa associação. A existência de um território definido não implica uma condição de imutabilidade. As fronteiras desse território podem não ser fixas nem precisas, ou podem mesmo encontrar-se em constante mutação, como ocorre com tribos nômades. O importante é que, em cada momento, exista um território sobre o qual a associação se estende e que permita definir quem está dentro e quem está fora dela;

(b) embora sejam elementos básicos de todas as asso90 ciações políticas, a capacidade e a disposição para o uso da força não são condições exclusivas destas. A defesa do território pode ser divida entre várias comunidades familiares ou de vizinhos, ou podem mesmo formar-se comunidades de guerreiros com o único objetivo de repelir uma ameaça externa. O que define a associação política é que sua capacidade e disposição para o uso da força não é eventual, ela encontra-se permanentemente organizada com esse propósito e exerce essa capacidade sobre um território. Tal capacidade reside em um poder próprio da associação que não pode ser decomposto no poder de suas partes. $\mathrm{O}$ desenvolvimento da associação política implica, portanto, um desenvolvimento do caráter institucional da relação associativa contínua, que dê a esta a estabilidade necessária para ter lugar de modo contínuo e permanente;

(c) a associação política existe apenas na medida em que suas ordens regulam as mais variadas atividades humanas. Tais ordens não restringem seu alcance às atividades econô- 
micas comuns necessárias para a satisfação das necessidades coletivas, nem dispõem exclusivamente sobre bens materiais e serviços. Não há, por definição, nenhuma atividade humana que não possa estar condicionada por normas e regulamentos amparados no uso da força ou na ameaça de utilizá-la. A capacidade e a disposição de uso da força física fazem com que a associação política vá além dos limites da "associação econômica" e estenda seu domínio sobre as demais esferas da vida, inclusive aquelas de âmbito privado, como as relações entre marido e esposa, pais e filhos;

(d) devido a seu caráter contínuo e permanente, toda associação política requer uma disposição efetiva sobre os meios necessários para aplicar a coação física: o quadro administrativo pessoal e os recursos administrativos materiais (cf. Weber, 1999, v. 2, p. 527). Para Weber, toda dominação manifesta-se como administração, ou seja, para viabilizar-se, ela necessita de um círculo de pessoas que, interessadas em manter a dominação e acostumadas a obedecer às ordens dos líderes, estejam permanentemente à disposição destes, encarregando-se das funções "técnicas" necessárias para conservá-la e distribuindo entre si os poderes de coação e mando necessários para o exercício dessas funções.

Foi com base nesse conceito de associação política que Weber apresentou seu conceito de Estado. A ideia do Estado como associação está presente na literatura da época e pode ser encontrada, claramente, na obra de Georg Jellinek (2000, p. 194), o qual define o Estado, do ponto de vista social, como "a unidade de associação (Verbandseinheit) dotada originariamente de poder de dominação e formada por homens assentados em um território". Compreendendo o Estado como uma forma particular de associação política, Weber apresentou de modo mais preciso o conceito deste naquele capítulo tardio, no qual os conceitos sociológicos fundamentais estavam expostos: "Uma empresa com caráter de instituição política denominamos Estado quando e 
na medida em que seu quadro administrativo reivindica com êxito o monopólio legítimo da coação física para realizar as ordens vigentes"10 (Weber, 1999, v. 1, p. 34).

A ideia de Estado como uma "comunidade humana" (menschliche Gemeinschaft), presente em Politik als Beruf e que ainda tinha lugar na segunda parte de Wirtschaft und Gesellschaft, cedia lugar nas soziologische Kategorienlehre ao conceito de Estado como "associação política" (politischer Verband). O conceito de associação política não era, entretanto, contraposto ao de comunidade humana. A distância no tempo entre as duas versões não era tão grande para uma mudança tão radical. Fica claro no tratamento dado por Weber ao conceito de associação que esta era uma forma de comunidade. O deslocamento conceitual tem assim o propósito de tornar o conceito de Estado mais preciso e antecedia a três variantes importantes que apareciam nesta nova definição: em primeiro lugar, nela havia uma nova ênfa92 se no caráter institucional da empresa estatal; em segundo, a nova redação destacava que o monopólio legítimo da coação física era exercido pelo quadro administrativo; em terceiro, apresentava como finalidade do Estado a realização das ordens vigentes.

Os significados atribuídos aos conceitos de empresa (Betrieb) e instituição (Anstalt) são fundamentais para compreender melhor esse novo conceito weberiano de Estado. O sociólogo alemão define empresa (Betrieb) como "uma ação contínua que persegue determinados fins" (Weber, 1999, v. 1, p. 32). O conceito serve para destacar o caráter duradouro e, ao mesmo tempo, dinâmico de um poder de comando contínuo que é aplicado em uma esfera determinada de atividades com vistas à realização de uma ordem vigente. A definição de Estado como empresa estabelecia

\footnotetext{
${ }^{10}$ No original: "Staat soll ein politischer Anstaltsbetrieb heißen, wenn und insoweit sein Verwaltungsstab erfolgreich das Monopol legitimen physischen Zwanges für die Durchführung der Ordnungen in Anspruch nimmt" (Weber, 1980, p. 29).
} 
uma forte e límpida analogia da atividade política com a atividade econômica, analogia essa que seria fundamentaria a definição do Estado racional, aquele cujo quadro administrativo encontra-se organizado burocraticamente.

Também importante é o conceito de instituição (Anstalt), "uma associação cuja ordem estatuída se impõe, com (relativa) eficácia, a toda ação com determinadas características que tenha lugar dentro de determinado âmbito de vigência” (Weber, 1999, v. 1, p. 32). Dusza (1989, p. 76) destacou o caráter compulsório e quase corporativo que as instituições assumiam na sociologia da dominação weberiana. Mas chama a atenção para o fato de Weber ter preferido utilizar esse conceito em vez do conhecido conceito de corporação (Körperschaft). A definição do Estado como uma corporação era frequente na Staatslehere alemã e antes mesmo dela. Segundo o historiador Otto von Gierke (1913, p. 69), um autor ao qual Weber frequentemente recorria em seus estudos, os conceitos de Estado e Império estavam, para o pensamento político medieval, subsumidos no conceito de corporação. Jellinek (2000, p. 196), por sua vez, definia juridicamente o Estado como "a corporação (Körperschaft) formada por um povo, dotada de poder de mando originário e assentada em determinado território”, embora rejeitasse a noção de Estado como instituição.

O conceito weberiano de instituição (Anstalt), entretanto, tem a vantagem sobre o conceito de corporação (Körperschaft) por ser o de instituição mais abrangente. A corporação é uma forma particular de instituição, ou seja, embora toda corporação seja uma instituição nem toda instituição é uma corporação. No pensamento político alemão do início do século XX, a corporação era compreendida “como uma comunidade de indivíduos a que a ordem jurídica impõe deveres e confere direitos subjetivos que não podem ser vistos como deveres ou direitos dos indivíduos que formam esta corporação como seus membros, mas competem a esta 
mesma corporação" (Kelsen, 2003, p. 194). A corporação era, desse modo, concebida como uma pessoa jurídica, como bem entendeu Jellinek, que inseriu o conceito de corporação em um conceito jurídico de Estado ${ }^{11}$.

O pressuposto implícito desse conceito de corporação era seu caráter autônomo. Na medida em que a definição dos direitos e deveres dos membros lhe pertencia, tem-se que esta seria para seus membros um sujeito do direito, daí seu caráter de pessoa jurídica. Mas esse caráter de pessoa jurídica não é extensivo a todas as instituições. Não é difícil pensar em instituições que não assumem a forma de um ente jurídico; bem como instituições heterônomas e mesmo heterocéfalas, como, por exemplo, as províncias canadenses citadas por Weber (1999, v. 1, p. 31), que teriam não apenas suas normas como também seus governantes definidos por um poder externo. Por outro lado, na Staatslehere alemã, o conceito de corporação carregava com frequência 94 uma conotação de forte teor organicista, que certamente não agradava a Weber, conotação essa que estava ausente do conceito de instituição. Justificava-se, então, a opção pelo conceito de instituição (Anstalt) no lugar de recorrer ao conceito mais comum de corporação (Körperschaft).

O conceito de instituição foi se tornando mais preciso conforme Weber o foi aproximando do conceito de empresa (Betrieb), dando origem à noção de "empresa com caráter de instituição política” (politischer Anstaltsbetrieb). Neste conceito completamente novo, que tem lugar exclusivamente no âmbito das soziologische Kategorienlehre weberianas, era possível destacar, ao mesmo tempo, o caráter contínuo e compulsório (quase corporativo) do Estado. O conceito de instituição (Anstalt) ganhava, então, um novo dinamismo quando associado ao conceito de empresa (Betrieb) (cf. Dusza, 1989, p. 76).

\footnotetext{
${ }^{11}$ No conceito sociológico de Estado, como visto, este não era uma corporação e sim uma "unidade de associação" (Verbandseinheit).
} 


\section{O Estado como empresa (Betrieb)}

Para Max Weber, a empresa estatal racional e a empresa econômica racional germinaram no mesmo solo - o Ocidente -, e, por isso, partilharam de uma história comum. O nexo estabelecido nessa análise entre o florescimento da moderna empresa capitalista e o desenvolvimento do Estado moderno é muito forte. Segundo o sociólogo, o empreendimento capitalista necessitava, para prosperar, que o Estado repousasse sobre um funcionalismo especializado e um direito racional, que não tiveram lugar no Oriente. Desse modo, a tendência ao progresso da economia em direção às formas modernas da empresa racional foi acompanhada de uma tendência ao progresso da política em direção às formas modernas do Estado racional.

A simetria foi destacada pelo próprio Weber (1982, p. 102): "a totalidade do processo é um paralelo completo ao desenvolvimento da empresa capitalista". O rigor com o qual o sociólogo alemão desenvolveu esse paralelismo é surpreendente. As questões fundamentais para o autor de Wirtschaft und Gesellschaft diziam respeito à separação dos trabalhadores/funcionários dos meios de produção/ administração e à concentração desses meios em um único ponto. Assim como a moderna empresa capitalista teria como pressuposto a separação do trabalhador dos meios de produção, o Estado moderno teria como pressuposto a separação do quadro administrativo dos meios administrativos.

No Estado moderno, o quadro administrativo estaria separado dos meios de administração - dinheiro, prédios, material bélico etc. -, tornando viável uma administração impessoal da ordem pública. A associação política moderna se diferenciaria da associação política estamental à medida que, nesta última, os meios administrativos materiais estivessem total ou parcialmente nas mãos do quadro administrativo. $\mathrm{O}$ encerramento desses meios na esfera privada dos 
administradores e a subordinação do uso deles aos interesses privados tornaria impossível uma administração racional e impessoal, capaz de dar conta das tarefas crescentemente complexas e abrangentes relacionadas com a manutenção da ordem, como a manutenção da paz ou a realização da guerra (cf. Weber, 1999, v. 2, p. 528).

A dependência hierárquica do trabalhador assalariado, do funcionário administrativo e técnico, e também do servidor público e do soldado se deveria ao fato de os meios indispensáveis para a consecução da empresa e para o ganho da subsistência estarem nas mãos do empresário ou do mandatário político. Essa separação do quadro administrativo dos meios de administração permitiria falar de um Estado moderno e racional. Segundo Weber (1999, v. 2, p. 528), uma "associação política, em que os meios administrativos materiais se encontram integral ou parcialmente no poder próprio do quadro administrativo dependente é 96 uma associação organizada 'estamentalmente'”. Enquanto os "funcionários" do Estado fossem, ao mesmo tempo, proprietários dos meios de administração, o que é característico de formas políticas pré-modernas, não haveria as condições necessárias para a existência de um Estado racional fundamentado na crença na legitimidade da lei e na competência especializada dos funcionários.

Assim, em seu desenvolvimento, o Estado moderno necessitou expropriar os detentores originais dos meios de administração. A apropriação da coleta de imposto exigiu superar os sistemas de arrendamento de cargos e tributos que havia caracterizado, por exemplo, os sátrapas orientais. Por meio destes, o senhor havia descarregado sobre os ombros do funcionário arrendatário "o trabalho de transformar as receitas em espécie em dinheiro" (Weber, 1999, v. 2, p. 205). Ao mesmo tempo que permitiam prever o volume da receita obtida e organizar, a partir dessa previsão, a administração, mecanismos como esse "têm a tendência a 
afrouxar o mecanismo burocrático, especialmente a debilitar a subordinação hierárquica” (p. 207). A contrapartida desse fato foi o incremento dos meios coativos de manutenção da hierarquia e da disciplina, gerando grande instabilidade. Uma administração eficaz, baseada no estabelecimento e conservação de um eficiente aparelho burocrático, teria exigido a apropriação por parte da administração estatal da coleta de impostos mediante a expropriação dos arrendatários e a separação da esfera privada do funcionário da atividade estatal. Processo semelhante teria ocorrido na conformação dos modernos exércitos, nos quais a centralização das atividades de convocação, organização e direção do exército foram cruciais nesse processo.

Enquanto não tivesse tido lugar uma completa separação entre funcionários e meios de administração não seria possível concentrar no Estado todos os recursos de organização política necessários para que este exercesse o monopólio da coação física legítima. Enquanto não houvesse essa separação, não seria possível falar, portanto, de Estado no sentido moderno da palavra. A associação política assumiria, assim, formas pré-modernas. Na situação, própria do Estado moderno, o "domínio efetivo [...] encontra-se, necessária e inevitavelmente, nas mãos do funcionalismo, tanto do militar quanto do civil" (Weber, 1999, v. 2, p. 529).

Destaque-se que, para Weber, no Estado moderno, a burocracia governa, pois o poder é exercido na rotina da administração. A definição que apresentava no âmbito de suas soziologische Kategorienlehre, embora sintética, já destacava isso na afirmação de que a violência legítima era exercida pelo quadro administrativo. O progresso em direção ao funcionalismo burocrático (formalismo de emprego, salário, pensão, promoção, treinamento especializado, divisão funcional do trabalho, áreas bem definidas de jurisdição, processos de documentação e estrutura hierárquica) era concebido como padrão de modernização do Estado. O avanço da 
burocracia poderia ser percebido na administração militar e civil, na Igreja e nas grandes empresas privadas, bem como no maior crescimento dos funcionários assalariados em relação aos operários.

Estado racional (capitalista) e empresa capitalista (racional) eram para Weber (1999, v. 2, p. 530.) formas perfeitamente homólogas: "o Estado moderno, do ponto de vista sociológico, é uma 'empresa', do mesmo modo que uma fábrica: precisamente esta é sua qualidade historicamente específica”. Essa passagem encontra-se em um importante texto de 1918, "Parlament und Regierung im neugeordneten Deutschland" ("Parlamento e governo em uma Alemanha reordenada") (cf. Weber, 1988, p. 306). O contexto original é esclarecedor, uma vez que nele o sociólogo alemão focalizou sua investigação nas condições necessárias para a eficácia da dominação burocrática. A eficácia do Estado-empresa era uma condição necessária para a manutenção da ordem social, do mesmo modo que a eficácia da fábrica-empresa era uma condição para uma gestão econômica bem-sucedida. Mas essa eficácia seria sempre limitada pelo caráter burocrático da gestão política e econômica.

A capacidade dirigente e empreendedora que caracterizariam tanto o homem de negócios como o homem de Estado não se encontraria presente no funcionário da administração pública. Enquanto este, tanto na empresa como no Estado, agiria de acordo com regras previamente estabelecidas, as quais está obrigado a seguir independentemente dos resultados desta ação, o dirigente político ou econômico agiria sempre com vistas à obtenção do melhor resultado possível. A ação que encontra seu único fundamento em um ethos das funções seria sempre ineficaz:

Quando uma figura dirigente é um “funcionário”, segundo o espírito de sua direção, mesmo um funcionário muito competente - alguém portanto que está acostumado a 
realizar seu trabalho de acordo com os regulamentos e a ordem dada, cumprindo honestamente seus deveres então não presta para ocupar uma posição à cabeça de uma empresa da economia privada nem à cabeça de um Estado (Weber, 1999, v. 2, p. 543; cf. tb. Weber, 1988).

A analogia entre o Estado-empresa e a fábrica-empresa não poderia deixar de alarmar Weber, pois, quando uma fábrica é administrada de modo ineficaz por uma burocracia, o resultado não pode deixar de ser sua falência. Mas qual pode ser o resultado quando o Estado é administrado de modo ineficaz? O que pode significar a falência de um Estado? Em "Parlament und Regierung...", a analogia entre o Estado-empresa e a fábrica-empresa tem, portanto, o caráter de uma advertência, uma advertência que tinha lugar em meio à convulsão social que se manifestava cotidianamente nas ruas de Berlim à época.

As novas ênfases postas pela tardia definição weberiana de Estado destacavam a coincidência daquela drástica eficácia dos meios de coação com a possibilidade de uma ordenação racional de sua aplicação (cf. Weber, 1999, v. 2, p. 157). No Estado moderno, a violência seria legítima uma vez que se apoiaria na crença extremamente difundida entre os membros da associação, de que ela teria lugar em conformidade com a lei. Uma vez que toda dominação se manifestaria e funcionaria como administração (cf. Weber, 1999, v. 2, p. 193), a dominação estatal encontraria sua expressão em um aparelho institucional e em um quadro administrativo que definissem seu alcance e seus limites. A repartição dos poderes de mando e coação que são próprios da associação política estatal ocorreria, desse modo, de acordo com regras preestabelecidas e cristalizadas em instituições. 
O Estado seria, assim, uma "relação de dominação de homens sobre homens" (cf. Weber, 1999, v. 2, p. 526), relação esta que estaria apoiada no monopólio dos meios de coação legítima. A questão da legitimidade torna-se fundamental, já que apenas ela seria a garantia última da subsistência de uma associação política. A força e a violência são essenciais na vida política, segundo Weber. Essa afirmação da força e da violência como categorias irredutíveis e autônomas da política aproximou sociólogo alemão de Nicolau Maquiavel. Assim como o secretário florentino, Weber também considerava que a política se encontrava em uma relação tensa, senão antinômica, com os princípios de uma ética religiosa (cf. Mommsen, 1992, p. 20). Uma interpretação ligeira dessa afirmação poderia levar a considerá-lo um rude Realpolitiker. Também Maquiavel recebeu, por razões muito parecidas, essa acusação, mas para ambos ela era injusta. Para o sociólogo alemão, de fato, o poder é vontade de 100 potência, mas os sistemas de dominação nos quais o poder se afirma necessitam ser legítimos para serem duráveis. Não há dominação estável sem legitimação e, portanto, sem o reconhecimento daqueles que são dominados (cf. Vincent, 1998, p. 71).

O conceito de legitimidade referia-se, para Weber, à aceitação da validade de uma ordem de dominação. Tal definição não dizia respeito, portanto, a questões de ordem normativa baseadas em padrões morais e éticos considerados adequados ou aceitáveis na condução do governo. $\mathrm{O}$ que definiria a legitimidade de um sistema de dominação seria a disposição subjetiva de seus sujeitos e, nesse sentido, a capacidade desse sistema apresentar-se como consensual (cf. Mommsen, 1992, p. 21; Vincent, 1998, p. 71). O modo como Weber utilizava esse conceito tinha como pressuposto, portanto, sua neutralidade axiológica. Esse modo de definir o conceito de legitimidade provocou a crítica de vários intérpretes, que julgaram ser impossível um 
conceito de legitimidade que não fizesse referência a normas que permitissem comparar diferentes formas de dominação (cf., p. ex., Grafstein, 1981). Ao apelar para um conceito de legitimidade não normativo, Weber estaria, segundo afirmam, impedindo que fosse definida uma forma de dominação ilegítima. E não faltaram até mesmo aqueles que escreveram que seu argumento foi utilizado pelo nazismo para justificar uma existência supostamente legítima.

Mas o sociólogo alemão não estava preocupado em definir quais regimes políticos seriam legítimos e quais não. Sua questão principal era outra e dizia respeito aos "princípios últimos em que pode apoiar-se a 'validade' de uma dominação, isto é, o direito à obediência dos 'funcionários', por parte do senhor, e à dos dominados, por parte destes dois" (Weber, 1999, v. 2, p. 197). A questão fundamental era se a dominação era considerada legítima pelos dominados ou não. Como é sabido, para Weber o "progresso" científico teria um significado meramente técnico, não dizendo nada a respeito dos fins últimos desse progresso. Nessa perspectiva, caberia à ciência contribuir para a "tecnologia do controle da vida" e incrementar a clareza a respeito das relações entre meios e fins fazendo uso adequado de métodos de pensamento e instrumentos de investigação (cf. Weber, 1982, pp. 177-78). Coerente com seu método, Weber pretendia colocar-se em uma posição que lhe permitisse afirmar as consequências de certas formas políticas sem ter que recorrer para tal a um conceito normativo de legitimidade.

Os tipos ideais de dominação legítima definidos por Weber não eram, desse modo, arranjados em uma escala de legitimidade, nem colocados em uma linha de sucessão histórica. A dominação legal com quadro administrativo burocrático, assim como as demais formas de dominação, fundava-se na crença em sua legitimidade. Fundamentava-se na existência de um direito estatuído de modo racional, de um conjunto de regras abstratas, promulgadas com determinadas intenções 
e de acordo com as quais o senhor típico ideal mandaria, ao mesmo tempo que as obedeceria (Weber, 1999, v. 1, p. 142). Em tal situação, quem obedece se conformaria não ao senhor, mas à lei que ele expressa. Trata-se, portanto, de uma concepção na qual a política se encontra assentada no domínio das leis e não dos homens, e na qual a autoridade, para ser legítima, deveria ser legal, ou seja, deveria estar amparada na lei. O argumento de Weber não deixava de ser circular, uma vez que a dominação seria legítima se estivesse baseada em leis estatuídas, as leis seriam legítimas se fossem estatuídas e o ato de estatuir seria legítimo se tivesse lugar de acordo com a lei. A circularidade do argumento permitia a Weber rejeitar uma definição do Estado moderno e da dominação legal com base em seus objetivos ou em valores específicos (Bendix, 1962, p. 419).

Como visto, Weber recusou um conceito normativo de legitimidade. Pela mesma razão, rejeitou um conceito de 102 Estado baseado naquilo que o Estado deveria fazer - manter a paz e a segurança, garantir o bem comum, assegurar a propriedade, prover os súditos daquilo que é necessário para sua felicidade etc. -, bem como um conceito que se sustentasse naquilo que o Estado faz. Nada mais estranho à sociologia weberiana do que a explicitação de um conceito pela definição de uma função que deveria ter ou que é desempenhada. Se o Estado não pode ser definido por sua função é porque ele estaria apto a desempenhar um grande número de funções e porque não haveria quase função que ele já não tivesse desempenhado.

$\mathrm{O}$ que deveria ser feito para defender o indivíduo perante uma força de tal tamanho é a pergunta que Weber se fez em mais de uma ocasião. A essa pergunta, o sociólogo não poderia responder, mas solucionar o enigma seria obrigação do político. Ao cientista caberia, entretanto, dimensionar essa força e revelar seus efeitos sobre os indivíduos e a sociedade, bem como suas tendências; caberia apresentar 
as diversas alternativas disponíveis e as consequências decorrentes de cada uma delas. Weber já havia identificado os problemas, analisado as alternativas existentes e feito suas opções. Nesse ponto, cientista e político se aproximavam. Como cientista que nunca deixou de se preocupar com a política de modo realista, Weber sabia dos riscos que sua época enfrentava. Como compatibilizar o critério da eficácia da dominação política com a sua legitimidade? Esta era a pergunta que a sociologia weberiana do Estado procurava responder.

\section{Alvaro Bianchi}

é livre-docente do Departamento de Ciência Política da Unicamp.

\section{BIBLIOGRAFIA}

ANDRESKI, S. 1964. "Method and substantive theory in Max Weber". The British Journal of Sociology, v. 15, n. 1, pp. 1-18.

BENDIX, R. 1962. Max Weber: an intellectual portrait. New York: Anchor.

CLARKE, S. 1991. Marx, marginalism and modern Sociology. 2. ed. London: Macmillan.

COHEN, J.; HAZELRIGG, L. E.; POPE, W. 1975. "De-Parsonizing Weber: a critique of Parsons' interpretation of Weber's Sociology". American Sociological Review, v. 40, n. 2, pp. 229-41.

DAHRENDORF, R. 1959. Class and class conflict in industrial society.

Stanford: Stanford University.

DUSZA, K. 1989. "Max Weber's conception of the State”. International Journal of Politics, Culture and Society, v. 3, n. 1, pp. 71-105.

GRAFSTEIN, R. 1981. "The failure of Weber's conception of legitimacy: its causes and implications”. The Journal of Politics, v. 43, n. 2, pp. 456-72.

JELLINEK, G. 2000. Teoría general del Estado. México D.F.: Fondo

Económico de Cultura.

KELSEN, H. 2003. Teoria pura do direito. São Paulo: Martins Fontes.

LASSMAN, P. 2000. "The rule of man over man: politics, power and

legitimation”. In: TURNER, S. The Cambridge Companion to Weber.

Cambridge: Cambridge University. pp. 83-98.

MOMMSEN, W. J. 1990. Max Weber and German politics: 1890-1920.

Chicago: University of Chicago. 
. 1992. The political and social theory of Max Weber. Chicago: University of Chicago.

. 2000. "Max Weber's "Grand Sociology": the origins and composition of Wirtschaft und Gesellschaft: Soziologie”. History and Theory, v. 39, n. 3, pp. 364-83.

PIERUCCI, A. F. 2008. "Economia e sociedade: últimos achados sobre a 'grande obra' de Max Weber”. Revista Brasileira de Ciências Sociais, v. 23, n. 68, pp. 41-51.

SWEDBERG, R. 2003. "The changing picture of Max Weber's Sociology”. Annual Review of Sociology, v. 29, pp. 283-306.

VINCENT, J.-M. 1998. Max Weber ou la démocratie inachevée. Paris: Éditions du Félin..

VON GIERKE, O. 1913. Political theories of the middle ages. Cambridge:

Cambridge University.

WEBER, Marianne. 2003. Weber: uma biografia. Niterói: Casa Jorge.

WEBER, Max. 1964. The theory of social and economic organization. New York: The Free Press. . 1980. Wirtschaft und Gesellschaft. Grundriß der verstehenden

Soziologie. 5. ed. Tübingen: J. C. B. Mohr (Paul Siebeck). 1982. Ensaios de sociologia. 5 ed. Rio de Janeiro: Zahar. . 1988. Gesammelte politische Schriften. 5. ed. Tübingen: J. C. B. Mohr (Paul Siebeck). 1999. Economia e sociedade: fundamentos da sociologia compreensiva. Brasília: UnB. 2 v. 


\section{O CONCEITO DE ESTADO EM MAX WEBER}

\section{ALVARO BIANCHI}

Resumo: $\mathrm{O}$ artigo apresenta o conceito weberiano de Estado. Acompanhando diferentes formulações do conceito em momentos distintos da obra weberiana, destaca-se a importância que assume a valorização do enunciado presente no capítulo sobre as soziologische Kategorienlehre ("categorias sociológicas") de Wirtschaft und Gesellschaft (Economia e sociedade). Nesse capítulo, Weber explicita duas dimensões do Estado: (1) o Estado como associação política (politischer Verband) e (2) o Estado como empresa (Betrieb). Analisadas conjuntamente, tais dimensões permitiriam compreender a coincidência no âmbito estatal de uma drástica eficácia dos meios de coação, com a possibilidade de uma ordenação racional de sua aplicação, permitindo ir além das exposições tradicionais do conceito weberiano de Estado.

Palavras-chave: Estado; Associação Política; Empresa; Max Weber.

\section{MAX WEBER'S CONCEPT OF THE STATE}

Abstract: The article discusses the Weberian concept of State. Tracking different formulations of the concept at different times of Weber's work this article highlights the relevance assumed the statement present in the section about the soziologische Kategorienlehre in Wirtschaft und Gesellschaft. This section Weber made explicit the two dimensions of the State: (1) the State as a political association (politischer Verband), and (2) the State as an enterprise (Betrieb). Considered together, these dimensions allow to understand the coincidence inside the State of a drastic efficiency of the means of coercion, and the possibility of a rational ordering of their application, allowing to go beyond the traditional exposition of the Weberian concept of the State.

Keywords: State; Political Association; Enterprise; Max Weber. 